\title{
PREDICTING RANDOM LEVEL AND SEASONALITY OF HOTEL PRICES: A LATENT GROWTH CURVE APPROACH
}

\author{
GERMÀ COENDERS, JOSEP MARIA ESPINET, and MARC SAEZ
}

Department of Economics, University of Girona

\begin{abstract}
This article examines the effect on price of different characteristics of holiday hotels in the sun-andbeach segment, under the hedonic function perspective. Monthly prices of the majority of hotels in the five major tourist regions in the Spanish continental Mediterranean coast were gathered from May to October 1999, from the tour operator catalogues. Hedonic functions are specified as random-effect models and parameterized as structural equation models with two latent variables, a random peak season price and a random width of seasonal fluctuations. This model can be considered to be a latent growth curve model applied to seasonality rather than growth. Characteristics of the hotels were used as predictors of both latent variables in models fitted for each region separately. Hotel category, region, distance to the beach, availability of parking place, and room equipment have an effect on both peak price and seasonality. Three-star hotels have the highest seasonality and hotels located in the southern regions the lowest. This can be explained by a warmer climate in autumn in the southern regions. The model is fitted to the pooled data of all regions and expanded to include the effect of climate on prices.
\end{abstract}

Hedonic functions Hotel pricing Seasonality Latent growth curve models Random-effect models

The aim of this article is to study the effect on prices of the different characteristics or attributes of a holiday hotel in the sun-and-beach segment in Spain. This country constitutes the second tourist destination worldwide (Departament d'Indústria, 1999) and nowadays attracts mostly sun-seeking tourists, though the latest policies of both the industry and the government tend to foster other assets of the country such as culture, history, gastronomy, landscape, and monuments.

The relevant attributes of holiday hotels include, among others, category, services and facilities available to guests (e.g. swimming pool, garden, television in the room), attributes of the region in which they are located and, given the particular segment aimed at, likely climate. 
The effect of attributes on prices can be argued under different pricing models. The simple supplydemand model may be useful to determine long-term trends. However, in the short term, supply is inelastic (limited by the number of hotels and rooms), and thus only demand plays a role. Many hotel managers in the sun-and-beach segment recognize that they fix prices based mainly on demand during the previous year (Espinet, 1999). Economic theory suggests that utility to individuals depends on the characteristics of goods and services, which can be considered as baskets of attributes. Thus, demand price of any good or service is a function of attributes.

In the sun-and-beach segment, hotels usually negotiate prices with tour operators, but they also do so considering the observed demand during the previous years (Espinet, 1999). Even if, as sometimes suggested, the tour operators would impose the price (Taylor, 1995), demand and thus the hotel attributes would still be taken into account by them. The application of cost-oriented pricing is also common in the hotel sector (Chias, 1996; Witt \& Moutinho, 1994) and costs are also a function of attributes, at least of some of them. If, as is often done, tour operators delay their bookings and take advantage of their better information and bargaining position, economic theory suggests that prices will be close to the average variable cost.

Another important pricing model in the lodging market is yield management. Lieberman (1993, p. 36) defines yield management as a way of maximizing the profits when selling goods or services that cannot be stored, such as hotel rooms, by means of a joint management of stocks, quality, and price. In order to increase the producer surplus, yield management suggests to segment the market and to introduce price discrimination, both of which nowadays have become absolutely necessary in the lodging market. The most common discrimination variable is, of course, season (peak-load pricing), which will receive an explicit treatment in this article. Under the yield management perspective, quality, and thus attributes, are also related to price. Other pricing models are used in the hotel sector, albeit more rarely (see Espinet, 1999, for a review).

The main difficulty facing research on the value of attributes is that their price is unobserved as they are not separately traded in any market. Only the overall prices of hotel rooms including particular combinations of attributes are observed. In this context, hedonic methods (Rosen, 1974) constitute a natural and well-established solution in the economic literature (Cassel \& Mendelsohn, 1985; Halvorsen \& Pollakowski, 1981; Rosen, 1974). The analysis in this article draws upon this hedonic-price tradition of fitting statistical models to estimate the effects of attributes on price, which are interpreted as hedonic or implicit prices of the attributes or characteristics. The hedonic-prices method has already been successfully applied in the tourist sector (Clewer, Pack, \& Sinclair, 1992; Espinet, 1999; Espinet, Saez, Coenders, \& Fluvià, in press; JaimePastor, 1999; Sinclair, Clewer, \& Pack, 1990).

The study of hotel room pricing is quite complex because of seasonality, different price regimes (full board, half board, bed \& breakfast), and discounts and supplements on various grounds (additional bed for kids, single room, view to the sea, additional room equipment such as air conditioning, television, or mini bar). In addition, three types of prices are relevant in the Spanish tourist lodging market:

- Prices appearing in hotel guides published by official institutions such as the Spanish Tourism Office. These are official prices, which are seldom paid.

- Prices paid when the room is reserved by the traveler directly.

- Prices appearing in the catalogues of the tour operators. This coincides with the amount most tourists pay, as tour operators constitute the most frequent distribution channel for tourist hotels in the studied market segment (Espinet, 1999).

In Spain, tour operator prices are not systematically collected by any official tourist or statistical office. A comprehensive database of tour operator catalogue prices in the whole area of study was gathered for the first time and is used in this article. The database covers the five major tourist regions in the continental Spanish Mediterranean coast, accounting for $79 \%$ of beds offered. From north to south, they are: Costa Brava, Costa del Maresme, Costa Daurada, Costa Blanca, and Costa del Sol. All zones represent well the sun-and-beach segment, which is aimed at in this study.

Hedonic functions are estimated by means of latent growth curve models (LGCM) (e.g., McArdle, 
1988; McArdle \& Epstein, 1987; Meredith \& Tisak, 1990; Muthén, 1997; see Duncan, Duncan, Strycker, Li, \& Alpert, 1999, for an introduction), an extension of repeated measures analysis of variance and a particular case of the wider class of random-effects models, also known as mixed models, hierarchical models, or multilevel models (e.g., Laird \& Ware, 1982; see Bock, 1989, for an introduction). The model was used with the aims of:

- Estimating price level in each zone, controlling for differences in hotel characteristics across zones;

- Estimating seasonality curves in each zone, controlling for differences in hotel characteristics across zones;

- Finding the contribution of the hotel characteristics to price, within the economic hedonicprices tradition extended to collect both the effect on level and on seasonality; and

- Estimating the contribution of weather in the different zones on seasonality.

\section{Data}

Hotel prices were obtained daily from the catalogues of nine Spanish tour operators from May to October 1999. Foreign tour operators were disregarded, as their offer of Spanish hotels tends to be much narrower than that of Spanish operators. Besides, Espinet (1999) shows price differences to be very small with respect to foreign operators. The nine operators were selected on the basis of size and singularity; thus, the largest ones were selected on their own rights, and there were representatives of operators with and without their own network of travel agencies and of operators with remarkably high and remarkably low prices.

No sample of hotels was drawn but the whole population was studied. All hotels offering full board and appearing in at least one of the nine catalogues were included, which represents over $70 \%$ of the hospitality supply in the studied regions.

Prices were, in all cases, expressed in Euro per day and person in a double room with full board. Fortnight averages were computed and, in order to remove the effect of different hotels being offered by different sets of tour operators, prices were taken as the corrected hotel means in an additive analysis of variance model where hotels and operators were crossed fixed factors. The natural logs of the averages of the two prices registered every month were considered as endogenous variables. For May, only the second fortnight was considered, and for October, only the first was used. This resulted in the listwise missing value rate dropping from $12 \%$ to $8 \%$. The final number of hotels with complete information was 471 . Exploratory analyses were carried out and no outliers were detected.

The explanatory variables considered where those that were statistically significant in Espinet (1999), who used an initial list of 57 predictors:

- Size: number of rooms, log transformed.

- Category: dummy: H1: one-star hotels; H2: twostar hotels, H4: four-star hotels; three-star hotels are the reference category.

- Beach: dummy: 1 for hotels located right in front of the sea.

- Room: dummy: 1 for hotels whose rooms are equipped with at least one of the following without price surcharge: television, air conditioning, or mini-bar.

- Parking: dummy: 1 for hotels with parking place.

- Sport: dummy: 1 for hotels offering at least one of the following sport facilities: tennis, squash, golf, or mini-golf, with or without extra payment.

- Town: dummy: towns with fewer than 15 hotels were grouped into an "other" category. Neighbor towns with more than 15 and fewer than 30 hotels were merged if they were not significantly different according to a multivariate analysis of variance model of all price variables as dependent and the town and category as predictors.

Table 1

Available Hotels Per Zone

\begin{tabular}{lrr}
\hline & Count & $\%$ \\
\hline Costa Brava & 138 & 29.3 \\
Costa del Maresme & 60 & 12.7 \\
Costa Daurada & 71 & 15.1 \\
Costa Blanca & 121 & 25.7 \\
Costa del Sol & 81 & 17.2 \\
Total & 471 & 100.0 \\
\hline
\end{tabular}


Table 2

Nominal Variables: Proportions of Hotels With Given Characteristics and Star Categories Per Zone

\begin{tabular}{lcccccc}
\hline & Brava & Maresme & Daurada & Blanca & Sol & Overall \\
\hline Beach & 0.25 & 0.33 & 0.23 & 0.22 & 0.35 & 0.27 \\
Room & 0.49 & 0.47 & 0.85 & 0.78 & 0.83 & 0.67 \\
Parking & 0.75 & 0.58 & 0.83 & 0.55 & 0.77 & 0.69 \\
Sport & 0.24 & 0.23 & 0.32 & 0.22 & 0.51 & 0.29 \\
H1 & 0.11 & 0.07 & 0.00 & 0.11 & 0.00 & 0.07 \\
H2 & 0.14 & 0.28 & 0.14 & 0.25 & 0.09 & 0.18 \\
H3 & 0.67 & 0.58 & 0.72 & 0.52 & 0.67 & 0.63 \\
H4 & 0.08 & 0.07 & 0.14 & 0.12 & 0.25 & 0.13 \\
\hline
\end{tabular}

The values of the explanatory variables were extracted from the hotel guide published by the Spanish Tourism Office and from the tour operator catalogues. In case of conflict, the information of the hotel guide prevailed, except if more than two catalogues coincided in the availability of a service that was not included in the hotel guide.

Table 1 shows the distribution of the hotels across zones. Table 2 shows the proportion of hotels being in front of the beach, having special room equipment, parking place, sport facilities, and belonging to each of the categories, in each zone and overall. It can be seen that the mix of hotel characteristics is quite different for the different zones. In general, Costa Daurada and Costa del Sol seem to have the highest proportions of hotels of a high category and with additional services, though some services do not follow this general pattern. Table 3 shows the mean of the log transformed numeric variables, per zones and overall. In regard to prices, these means are depicted graphically in Figure 1, which shows large differences in price level across zones, which can- not be directly interpreted, as the hotel characteristic mix is heterogeneous across zones. Figure 2 represents the differences with respect to August, which can be interpreted as price reductions with respect to high season. This Figure is useful for viewing seasonality and shows that Costa Blanca and Costa del Sol, the southernmost areas with the warmest weather, have a distinct profile, although interpretation must wait until the effect of the hotel characteristic mix is controlled for.

\section{Model}

\section{Basic Specification}

Latent growth curve models (LGCM) can be used to represent the individual evolution in time. Each individual is allowed to have its own evolution curve as a function of time, without assuming that the parameters of the curve are equal for all individuals. The simplest LGCM would be a linear trend growth model:

$$
Y_{i t}=L_{i}+T_{i} C_{t}+D_{i t}
$$

Table 3

Continuous Log Transformed Variables: Means Per Zone

\begin{tabular}{lcccccc}
\hline & Brava & Maresme & Daurada & Blanca & Sol & Overall \\
\hline $\ln ($ size $)$ & 4.72 & 5.05 & 5.12 & 4.71 & 5.04 & 4.88 \\
$\ln \left(Y_{1}\right)$ (May) & 3.19 & 2.88 & 3.20 & 3.27 & 3.52 & 3.24 \\
$\ln \left(Y_{2}\right)$ (June) & 3.35 & 3.06 & 3.42 & 3.41 & 3.57 & 3.38 \\
$\ln \left(Y_{3}\right)$ (July) & 3.72 & 3.49 & 3.78 & 3.65 & 3.87 & 3.71 \\
$\ln \left(Y_{4}\right)$ (August) & 3.81 & 3.57 & 3.89 & 3.87 & 4.06 & 3.86 \\
$\ln \left(Y_{5}\right)$ (September) & 3.37 & 3.07 & 3.45 & 3.60 & 3.76 & 3.47 \\
$\ln \left(Y_{6}\right)$ (October) & 3.16 & 2.83 & 3.15 & 3.37 & 3.52 & 3.24 \\
\hline
\end{tabular}




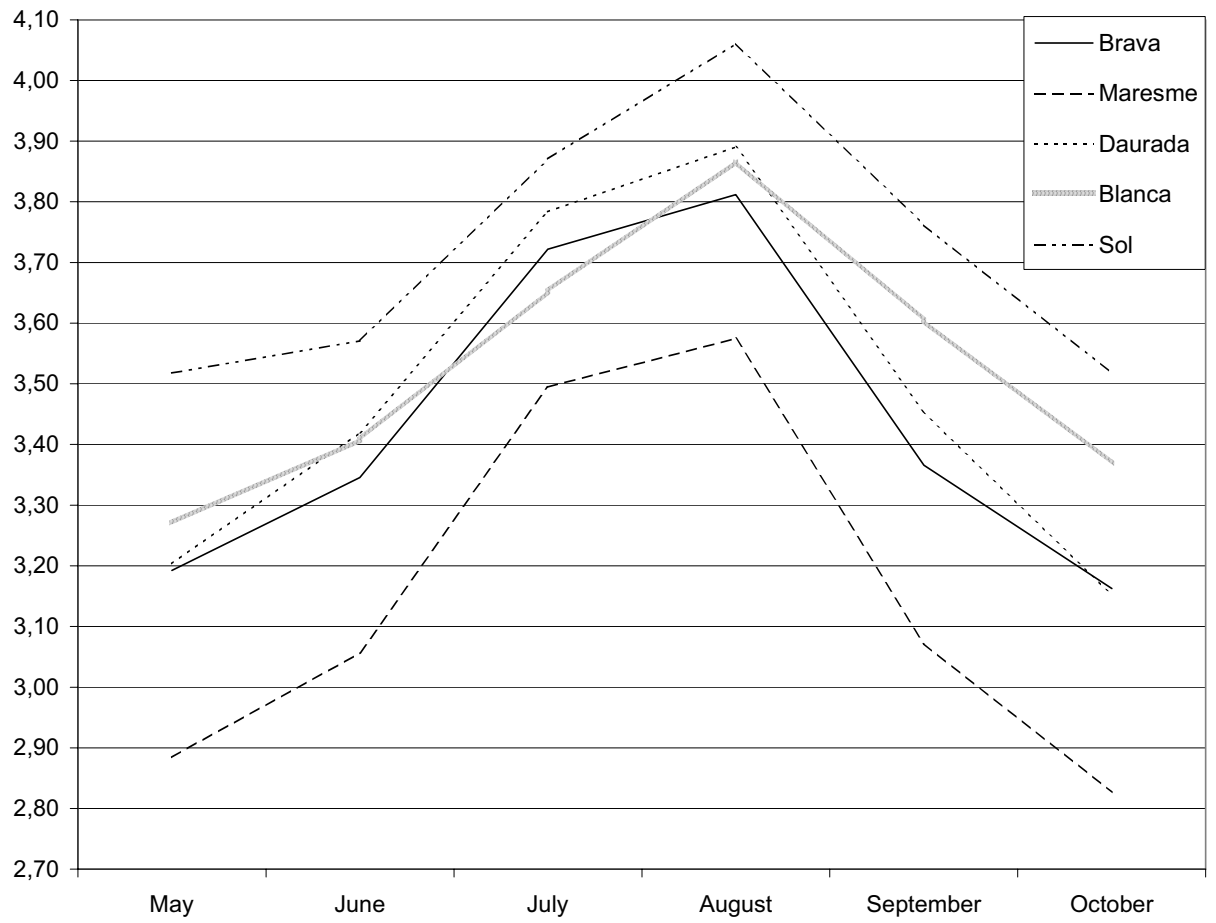

Figure 1. Average log prices in each zone and month.

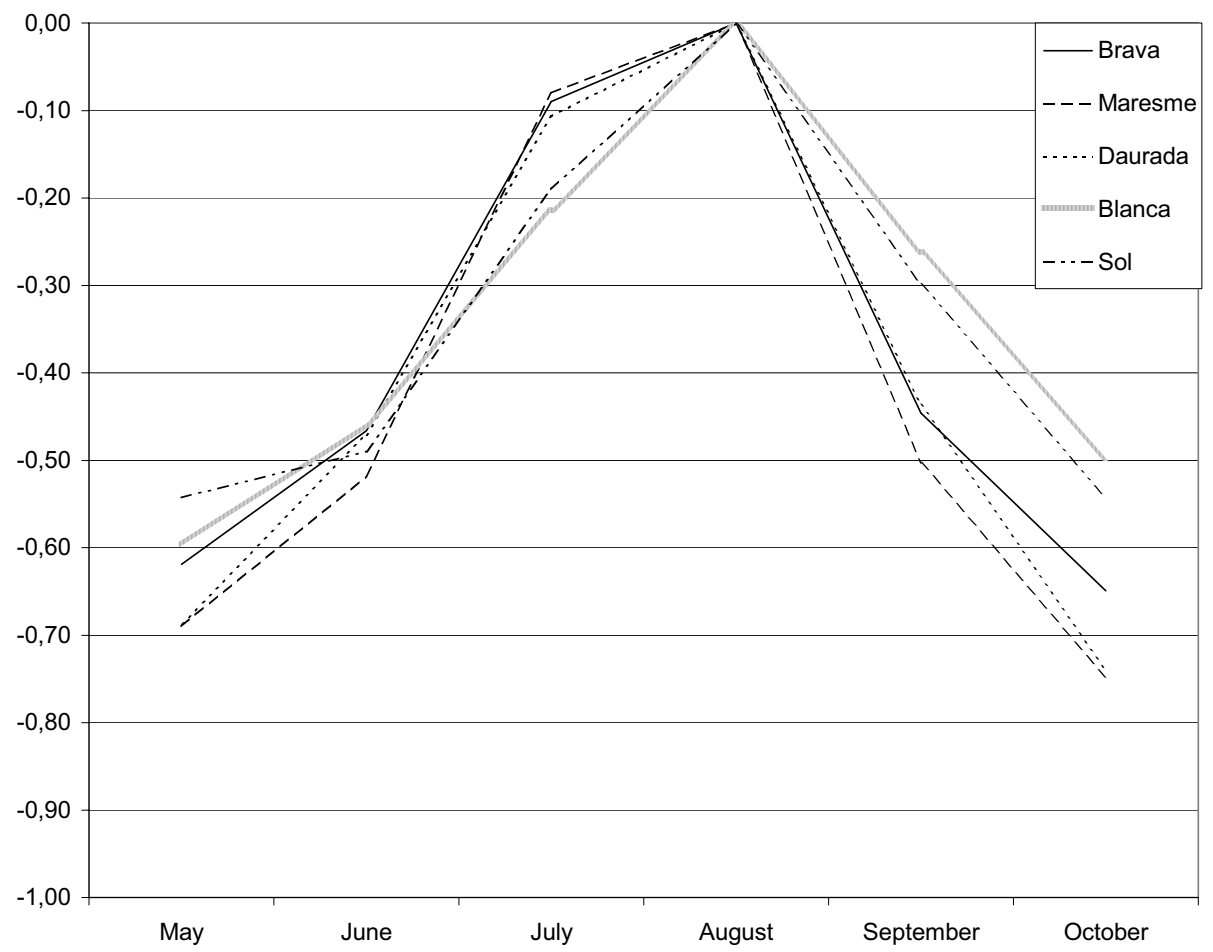

Figure 2. Average differences in log prices with respect to the peak month. 
where:

- $\quad i=1,2, \ldots, N$ represents the subject and $t=1,2, \ldots, T$ time.

- $Y_{i t}$ is the variable whose evolution is studied, measured at time $t$ for subject $i$.

- $\quad L_{i}$ is the fitted value for subject $i$ at $t=1$; that is, the random intercept of the growth curve for subject $i$, with mean $\mathrm{ML}$ and variance $\mathrm{VL}$ as free parameters.

- $T_{i}$ is the random slope of the trend growth curve for subject $i$, with mean MT and variance VT as free parameters.

- $\quad C_{t}$ represent time (e.g., $0,1,2,3, \ldots, T-1$ for a linear growth curve with measurements taken at regular intervals).

- $\quad D_{i t}$ is the disturbance term for subject $i$ at period $t$.

LGCM can be specified as mixed linear models, also called hierarchical linear models (HLM), but also as a particular case of structural equation models with latent variables (SEM) with mean structures (see Raudenbush, 2001, for an overview on SEM-LGCM; Batista-Foguet \& Coenders, 2000, or Bollen, 1989, as general SEM references; and Sörbom, 1974, for mean structures). Under the SEM approach, coefficients varying randomly across subjects are specified as latent variables, also known as factors. In this case, one factor must be specified for $L_{i}$ and one for $T_{i}$. The coefficients $C_{t}$ are then interpreted as constrained factor loadings. The loadings of $L_{i}$ are implicitly constrained to one. $D_{i t}$ is interpreted as uniqueness. The individual effects are represented by the factor scores and the average effects by the factor means. Applications of SEM to growth curves can be profusely found in psychology (McArdle \& Epstein, 1987), education (Willett \& Sayer, 1993), child development (Ghisletta \& McArdle, 2001), and health (Muthén, 2000), but are rare for economic variables (McArdle, 1998). Figure 3 shows a path diagram of the model specified as a SEM, for $T=6$.

In this article this type of model is used for economic panel data of hotels instead of individuals and to represent seasonality instead of trend. The model is then respecified as:

$$
Y_{i t k}=L_{i k}+S_{i k} C_{t k}+D_{i t k}
$$

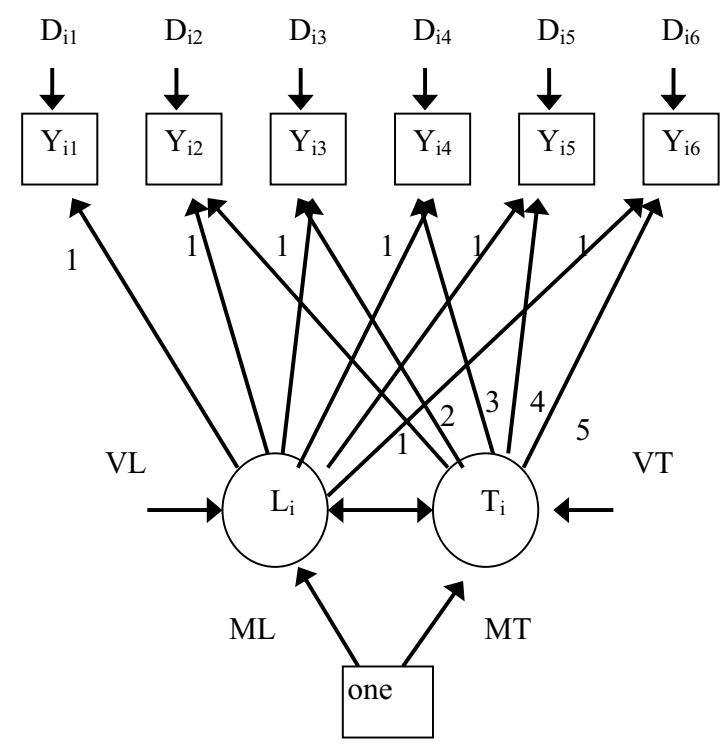

Figure 3. Path diagram of a linear LGCM for $T=6$.

where:

- $\quad i$ represents the hotel, $t$ time (month), and $k$ the zone (1: Costa Brava, 2: Costa del Maresme, 3: Costa Daurada, 4: Costa Blanca, 5: Costa del Sol). Random effects vary across hotels, while zones are treated as fixed effects by fitting the same model to multiple groups (Sörbom, 1974). All parameters are allowed to vary across zones and thus have a $k$ subscript.

- $\quad Y_{i t k}$ : natural log of price for the $i$ th hotel, $t$ th month, and $k$ th zone. These prices are represented by $T=6$ endogenous variables.

- $\quad S_{i k}$ : seasonality amplitude for hotel $i$ in zone $k$. Random effect varying across hotels represented by a latent variable with loadings $C_{t k}$ on the $Y_{i t k}$ variables with mean equal to 1 and variance VS as a free parameter.

- $\quad C_{t k}$ : seasonality profile for month $t$ in zone $k$. $C_{4 k}$ was set to 0 in order to set August (the peak month with the most revenues and occupation, and the closest to a market equilibrium situation, as most hotels are full) as reference for the price level. Thus, price level may be understood as peak level. The form of seasonality may be quite irregular, so that the $C_{t k}$ loadings are unconstrained (unlike the case was for the linear 
model described above, for which the loadings were constrained to $0,1,2, \ldots, T-1)$. The profile of seasonality is constrained to be the same for all hotels in the same zone. This implies, for instance, that peaks are located in the same month for all hotels. Only the peak level and the amplitude of the seasonal fluctuations are allowed to vary across hotels within zones, whereas between zones all parameters are allowed to change. Due to the natural log transform of the dependent variable, $e^{C t k}-1$ can be interpreted as percentage price reduction for months outside the peak season with respect to the peak season. As is usually done, the model could also be specified with the mean of $S_{i k}$ as a free parameter and one $C_{t k}$ loading constrained to 1 . This formulation is equivalent to ours but leads to less readily interpretable $C_{t k}$ coefficients.

- $\quad L_{i k}$ : peak price level for hotel $i$ at $t=4$ (August) in zone $k$. Random effect varying across hotels represented by a latent variable with unit loadings on the $Y_{i t k}$ variables, with mean ML and variance $\mathrm{VL}$ as free parameters.

- $\quad D_{i t k}$ : disturbance term for hotel $i$ during month $t$ in zone $k$ represented by the unique variances in the latent variable model, which can be interpreted as variation in monthly prices that is not explained. In this model, the source of unexplained variance is imposing prices to depend only on level and seasonality, seasonality being constrained to have a constant profile varying only in strength. Covariances between lagged disturbance terms can be modeled if needed. In our case, we assume $D$ to follow a heteroskedastic first-order moving average process.

A path diagram is displayed in Figure 4.

The model is extended to include $J$ numeric or dummy variables (those described in the data section) to predict the random effects (variables) $L$ and $S$ :

$$
\begin{gathered}
S_{i k}=1+\beta_{s 1 k} X_{1 i k}+\ldots+\beta_{s J k} X_{J i k}+U_{s i k} \\
L_{i k}=\beta_{L 0 k}+\beta_{L 1 k} X_{1 i k}+\ldots+\beta_{L J k} X_{J i k}+U_{L i k}
\end{gathered}
$$

For each zone, the model includes the parameters listed below:

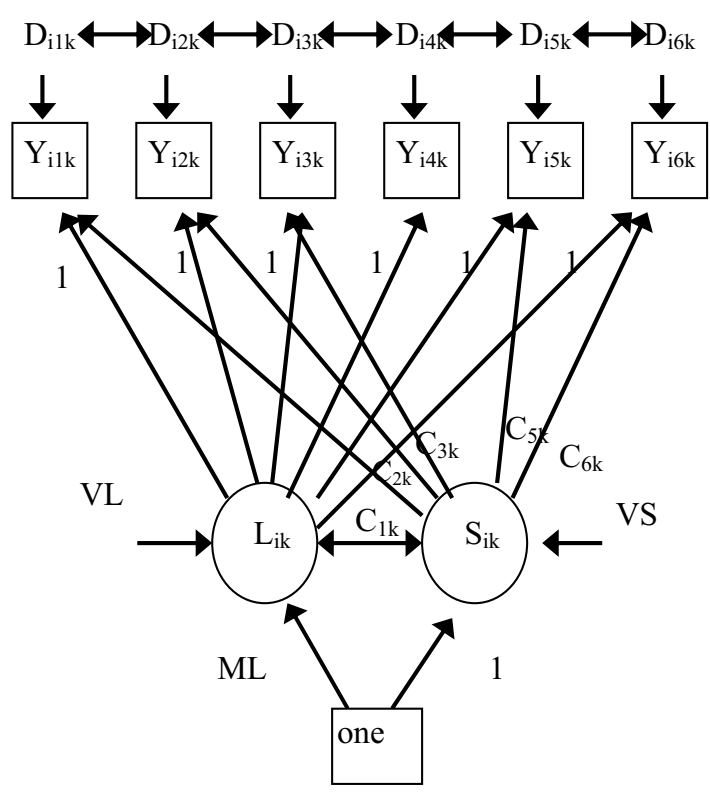

Figure 4. Path diagram of a seasonal heteroskedastic moving average $\mathrm{LGCM}$ for $T=6$.

- $\quad T-1 C_{1 k} \ldots C_{T k}$ seasonality coefficients $\left(C_{4 k}\right.$ is set to 0$) \cdot e^{C t k}-1$ is interpreted as percentage of price reductions outside the peak season.

- $T$ variances of $D_{1 k} \ldots D_{T k}$ accounting for heteroskedasticity and $T-1$ covariances between $D_{t k}$ and $D_{t-1 k}$ accounting for the first-order moving average process of serial correlation. $e^{2 \mathrm{SD}(D t k)}-1$ can be interpreted as the maximum (except for about $5 \%$ extreme cases) percent variation in prices above or below what is predicted by peak level and seasonality.

- $\quad 2 J \beta_{s j k}$ and $\beta_{L j k}$ regression slopes. Note the interpretation of the $e^{\beta L j k}-1$ transform of the coefficients as percentage change in the August price level for a unit increase in the predictor or for belonging to the category indicated by the dummy variable. This is due to the log-transformed dependent variable. Note also the interpretation of the $e^{\beta s j k}-1$ transform of the coefficients as percentage change in the seasonal indices. Positive $e^{\beta s j k}-1$ terms indicate wider seasonal fluctuations when increasing the values of the numeric predictors or when belonging to the category indicated by the dummy variable. The ability to predict the width of sea- 
sonality is one of the key advantages of this model.

- 2 variances and one covariance for the disturbance terms $U_{s}$ and $U_{L} . e^{2 \mathrm{SD}(U s)}-1$ can be interpreted as the maximum percent variation in seasonality amplitude that can occur above or below what is predicted. $e^{2 \mathrm{SD}(U L)}-1$ can be interpreted as the maximum percent variation in the August price level that can occur above or below what is predicted.

- $\quad 2$ intercept terms for the $L$ and $S$ random effects (latent variables). The intercept for peak level is $\beta_{L 0 k}$ and can be interpreted as the expected natural $\log$ of price in August for the reference group of the dummy predictors and the value zero of the numeric predictors. The transform $e^{\beta L 0 k}$ is of course more readily interpretable. The intercept for seasonality is constrained to 1 . This constraint does not reduce the generality of the model but is used only for identification and clarity purposes and makes $C_{1 k} \ldots C_{T k}$ apply to the reference group of the dummy predictors and the value zero of the numeric predictors.

\section{Inclusion of Weather Variables}

The shape of the zone seasonal profiles in Figure 2 suggests that southern zones (Costa Blanca and Costa del Sol), which can get good weather early in autumn, have lower price reductions in September and October. This suggests that tourists are willing to pay for good climate and this willingness to pay can also be estimated using hedonic functions in which weather variables act as explanatory. Since weather is constant or nearly constant for hotels in the same zone, the pooled data of all zones have to be analyzed in order to get estimates of the effect of an appropriate weather variable. The monthly average of maximum daily temperature was assumed to be a good indicator of the attractiveness of a tourist destination in the sun-and-beach segment. These temperatures were averaged over 1961-1990 in the closest observatories to the zones (Girona, Barcelona, and Malaga airports, Reus and Alicante) and are displayed in the first block of rows of Table 4. Of course, raising temperatures above a certain threshold may no longer be appreciated. It was assumed that increases in temperature are valued when they contribute to get a temperature below $27^{\circ} \mathrm{C}$, closer to $27^{\circ} \mathrm{C}$. Most people find temperatures around $25-26^{\circ} \mathrm{C}$ very pleasant and a maximum temperature of $27^{\circ} \mathrm{C}$ implies several hours of pleasant temperature every day. The gaps with respect to $27^{\circ} \mathrm{C}$ (second block of Table 4) were finally expressed in comparison to those of the Costa Brava (third block of Table 4), which plays the role of reference zone.

Equations 3 and 4 are now expressed as:

$$
\begin{gathered}
S_{i k}=1+\beta_{s 1} X_{1 i k}+\ldots+\beta_{s J} X_{J i k}+U_{s i k} \\
L_{i k}=\beta_{L 0}+\beta_{L 1} X_{1 i k}+\ldots+\beta_{L J} X_{J i k}+ \\
\delta_{L 2} Z_{2}+\delta_{L 3} Z_{3}+\delta_{L 4} Z_{4}+\delta_{L 5} Z_{5}+U_{L I K}
\end{gathered}
$$

where the $Z_{k}$ variables are zone dummies (the reference is zone 1: Costa Brava) used to predict price level. Note that the $k$ subscript has been dropped from the $\beta$ parameters. In these pooled models, the $\beta_{0}$ intercept is interpreted with respect to the reference zone and the $\beta_{j}$ slopes as a sort of average effect across zones. With log transformed data, the $e^{\delta L k}-1$ transforms of the coefficients are expected percentage price changes with respect to Costa Brava and referred to August.

Table 4

Weather Data Per Zones

\begin{tabular}{lccccc}
\hline \multicolumn{7}{c}{ Brava } & Maresme & Daurada & Blanca & Sol \\
\hline \multicolumn{7}{c}{ Average of } & Maximum & Daily Temperature & $\left.{ }^{\circ} \mathrm{C}\right)$ \\
May & 20.9 & 20.2 & 21.4 & 24.2 & 23.9 \\
June & 25.1 & 24.0 & 25.1 & 27.7 & 27.2 \\
July & 28.9 & 27.2 & 28.5 & 30.8 & 29.7 \\
August & 28.2 & 27.3 & 28.1 & 31.1 & 30.1 \\
September & 25.6 & 25.4 & 25.8 & 29.1 & 27.8 \\
October & 20.9 & 21.6 & 21.8 & 24.7 & 23.7 \\
Difference With & Respect to & $27^{\circ} \mathrm{C}$, When Negative & & \\
May & -6.1 & -6.8 & -5.6 & -2.8 & -3.1 \\
June & -1.9 & -3.0 & -1.9 & 0 & 0 \\
July & 0 & 0 & 0 & 0 & 0 \\
August & 0 & 0 & 0 & 0 & 0 \\
September & -1.4 & -1.6 & -1.2 & 0 & 0 \\
October & -6.1 & -5.4 & -5.2 & -2.3 & -3.3
\end{tabular}

Difference in the Difference With Respect to $27^{\circ} \mathrm{C}$ Compared to Costa Brava

\begin{tabular}{llclll} 
May & 0 & -0.7 & 0.5 & 3.3 & 3.0 \\
June & 0 & -1.1 & 0 & 1.9 & 1.9 \\
July & 0 & 0 & 0 & 0 & 0 \\
August & 0 & 0 & 0 & 0 & 0 \\
September & 0 & -0.2 & 0.2 & 1.4 & 1.4 \\
October & 0 & 0.7 & 0.9 & 3.8 & 2.8 \\
\hline
\end{tabular}


As regards the shape of seasonality, equation 2 is rewritten as:

$$
Y_{i t k}=L_{i k}+S_{i k} C_{t}+\eta_{t} F_{t k}+D_{i t k}
$$

where $F_{1 k}$ is the May difference in the gap with respect to $27^{\circ} \mathrm{C}$ for the $k$ th zone compared to the reference zone, $F_{2 k}$ the June difference, and so on. Thus, $e^{\eta t}-1$ is the percentage effect on price of a $1^{\circ}$ increase in temperature bringing temperature closer to $27^{\circ} \mathrm{C}$ during month $t$. This coefficient will have the effect of changing the price profiles with respect to that of Costa Brava and according to weather. It is constrained to zero in August for two reasons: first, temperatures are high enough in August in all zones; second, zone dummies freely affecting peak price level can account for heterogeneity across zones that cannot be explained by hotel category and services, and that should not get confounded with the effect of temperature. It is also constrained to zero in July (as temperatures are also consistently over $27^{\circ} \mathrm{C}$ ) and also in the reference zone Costa Brava.

\section{Estimation and Testing}

In this article, the LGCM are estimated as SEM. For equivalent LGCM, both HLM and SEM formulations yield nearly the same results (Hox, 2000). However, each formulation is more convenient under certain circumstances or makes certain model extensions possible. HLM are more flexible in terms of the hierarchical data structure. SEM are more flexible in terms of the model specification (Raudenbush, 2001; Rovine \& Molenaar, 2001) and, for instance:

- They enable researchers to use the general capabilities of SEM, such as variables measured with error by multiple indicators, indirect and simultaneous effects from predictors to growth factors, or even among growth factors related to different phenomena.

- They enable researchers to estimate the loadings of the growth factor, in our case the $C_{t}$ seasonal parameters. Our model could not have been estimated as HLM.

- They make it possible to compute overall goodness of fit indices that compare the fit of the model with that of a saturated model.
- They are more flexible in terms of heteroskedastic and autocorrelated error structures, though this seems to be a temporary limitation of HLM software.

Prior disadvantages of the SEM approach regarding the presence of missing data have long been overcome by new developments (Enders \& Bandalos, 2001; Graham, Taylor, \& Cumsille, 2001; Wothke, 2000; Yuan \& Bentler, 2000), which indirectly allows SEM to treat data with individually varying observation times.

The Mplus program (Muthén \& Muthén, 1998) was used for estimating the models by full information maximum likelihood under the assumption that $\log$ prices are normally distributed conditional on predictors. Possible deviations from normality do not affect the consistency of estimates, but only of standard errors and test statistics (Satorra, 1990). This article can be considered to be a population study, in which models and curves are used to approximate the population data rather than to estimate the parameters of an underlying population model. So, no use will be made of confidence intervals or standard errors, but only of descriptive goodness of fit indices, such as $R^{2}$ and the standardized root mean squared residual correlation (SRMSR). Though an early goodness of fit measure, the SRMSR has been found to compare well with more modern test-based alternatives (Hu \& Bentler, 1998).

\section{Results of Modeling Each Zone Separately}

Individual models were fitted for each zone with all predictors and without weather variables or constraints across zones. These models were then simplified:

- The log of the number of rooms had no large effect in any of the zones for the $L$ factor and was dropped with very minor reductions in the $R^{2}$ values. Actually, this variable does not measure any service of the hotel or any benefit for the consumer, and thus its presence in the model may be misleading.

- Only two towns had any substantial effect and all towns were dropped from all models in order to preserve the comparability of the predictor sets, as specific towns are located in only 
one zone. The reductions in the $R^{2}$ for the $S$ and $L$ factors were minor.

- The remaining variables had substantial effects in at least one zone and were preserved in all of them in order to keep the predictor sets comparable.

The fit of the models was excellent. The minimum $R^{2}$ for the $Y$ variables was 0.89 , thus showing the good fit of prices to a common seasonality shape within each zone. The minimum $R^{2}$ for the $L$ factor was 0.52 . The minimum $R^{2}$ for the $S$ factor was rather low at 0.15 , thus suggesting that seasonal amplitudes may be harder to predict than absolute levels of price. Values of SRMSR below 0.05 are considered acceptable. This threshold is exceeded by none of the zones. Table 5 shows the estimates, transformed as percentage changes, and fit indices. Effects resulting in price differences above $5 \%$ are shown in bold.

The first part of the table shows the transformed $e^{C t k}-1$ seasonality coefficients for a three-star hotel without any of the characteristics represented by the dummy variables. The estimated percentage reductions in prices with respect to August range from $50 \%$ to $59 \%$ in May, from $41 \%$ to $46 \%$ in June, from $8 \%$ to $23 \%$ in July, from $27 \%$ to $43 \%$ in September, and from $46 \%$ to $62 \%$ in October. Low season prices thus can be about half of the high season ones, or even less, if one considers that special offers and discounts are more frequent in the low season and do not appear in the catalogues. Travelers who can make arrangements to have holidays out of the peak season and are not so worried about weather conditions can make huge savings by avoiding the summer months.

The raw $C_{t}$ seasonality coefficients are represented graphically for each zone (Fig. 6), together with the estimated expected log prices (Fig. 5), which are comparable to Figures 2 and 1 except for the fact that both graphs now refer to a constant type of hotel for all zones, namely a three-star hotel without any of the services represented by the dummy variables. The graph of the expected log prices is markedly different from Figure 1. The graph of seasonality coefficients has about the same shape of Figure 2, but coefficients tend to be larger in absolute value. Once more, Costa del Sol and Costa Blanca exhibit a distinctive pattern in having less marked seasonality in September and October and more marked seasonality in July.
The second part of the table shows the equations predicting the August price level. The transformed $e^{\beta L 0 k}$ intercepts refer to the price in Euro for a threestar hotel without any of the services represented by the dummy variables, and show Costa Daurada, Costa Blanca, and Costa del Sol to be more expensive than Costa Brava and Costa del Maresme. As regards the transformed $e^{\beta L j k}-1$ slopes for the star category variables, one-star hotels are on average between $21 \%$ and $32 \%$ cheaper than three-star hotels, two-star hotels are on average between $6 \%$ and $18 \%$ cheaper than three-star hotels, and four-star hotels are on average between $30 \%$ and $68 \%$ more expensive than three-star hotels. Some differences can be observed across zones, and price differences between the lower categories and the reference are highest in Costa Blanca, while price differences between the higher category and the reference are highest in Costa Brava.

Price is not only determined by category, but other attributes also play a role. All attributes have a positive contribution on price for all zones except for a couple of anomalous results, which, fortunately, are among the values in the low range. The contributions tend to be around or above $+5 \%$ in the majority of zones for all attributes except sport facilities. Some differences in the contribution of attributes to price can be observed across zones and, overall, in Costa Brava all attributes have the highest effect on peak price. Hotel managers in this zone should then be the most sensitive to the attributes they are offering. The results of each of the zones can thus be the most useful to hotel managers, as some zones can be sufficiently different from others to attract visitors valuing attributes in a different way. As regards to the situation in front of the beach, the differences across zones can also be explained by the fact that in some zones there is no free urban soil available in front of the beach.

The next part of the table shows the transformed $e^{\beta s j k}-1$ slopes of the equations predicting the amplitude of seasonal fluctuations. Percentage lowseason price reductions are smaller for 1-, 2-, and four-star hotels than for three-star hotels, which suggests that four-star hotels are always expensive and one- and two-star hotels always cheap. The presence of attributes also tends to decrease the amplitude of seasonality, thus showing that attributes do not only increase revenues through an 
Table 5

Estimates of Individual Models Per Zones

\begin{tabular}{|c|c|c|c|c|c|}
\hline & Brava & Maresme & Daurada & Blanca & Sol \\
\hline \multicolumn{6}{|l|}{$e^{C t k}-1$} \\
\hline May & -0.500 & -0.520 & -0.591 & -0.519 & -0.498 \\
\hline June & -0.407 & -0.423 & -0.458 & -0.431 & -0.463 \\
\hline July & -0.095 & -0.082 & -0.128 & -0.230 & -0.213 \\
\hline August & - & - & - & - & - \\
\hline September & -0.393 & -0.414 & -0.433 & -0.276 & -0.315 \\
\hline $\begin{array}{l}\text { October } \\
e^{\beta L 0 k}\end{array}$ & -0.517 & -0.548 & -0.618 & -0.457 & -0.498 \\
\hline Intercept & 37.114 & 34.918 & 45.150 & 45.422 & 48.183 \\
\hline \multicolumn{6}{|l|}{$e^{\beta L j k}-1$} \\
\hline Beach & 0.124 & -0.031 & 0.065 & 0.066 & 0.063 \\
\hline Room & 0.091 & 0.096 & 0.012 & 0.053 & 0.051 \\
\hline Parking & 0.133 & 0.011 & 0.051 & 0.093 & 0.047 \\
\hline Sport & 0.106 & 0.055 & -0.061 & 0.028 & 0.044 \\
\hline $\mathrm{H} 1$ & -0.210 & -0.207 & none in the zone & -0.319 & none in the zone \\
\hline $\mathrm{H} 2$ & -0.063 & -0.131 & -0.092 & -0.183 & -0.151 \\
\hline $\mathrm{H} 4$ & 0.684 & 0.481 & 0.411 & 0.302 & 0.385 \\
\hline \multicolumn{6}{|l|}{$e^{\beta s j k}-1$} \\
\hline Beach & -0.086 & -0.029 & 0.028 & -0.104 & -0.120 \\
\hline Room & -0.050 & -0.023 & -0.058 & -0.155 & -0.077 \\
\hline Parking & -0.021 & -0.029 & -0.120 & -0.049 & -0.038 \\
\hline Sport & 0.017 & -0.056 & -0.048 & 0.043 & -0.035 \\
\hline $\mathrm{H} 1$ & -0.129 & -0.104 & none in the zone & -0.026 & none in the zone \\
\hline $\mathrm{H} 2$ & -0.124 & 0.013 & -0.243 & 0.042 & 0.022 \\
\hline $\mathrm{H} 4$ & -0.188 & -0.045 & -0.173 & -0.138 & -0.211 \\
\hline \multicolumn{6}{|l|}{ Covariances } \\
\hline$L-S$ & -0.014 & 0.005 & -0.014 & -0.005 & -0.012 \\
\hline$D_{1}-D_{2}$ & 0.001 & 0.000 & 0.001 & 0.001 & 0.001 \\
\hline$D_{2}-D_{3}^{2}$ & 0.001 & 0.000 & 0.002 & 0.001 & 0.001 \\
\hline$D_{3}^{2}-D_{4}^{3}$ & 0.000 & -0.001 & 0.000 & 0.000 & 0.000 \\
\hline$D_{4}-D_{5}^{4}$ & 0.000 & 0.002 & -0.001 & 0.000 & 0.000 \\
\hline$D_{5}^{4}-D_{6}$ & 0.000 & 0.001 & -0.002 & 0.000 & 0.000 \\
\hline
\end{tabular}

Disturbances

\begin{tabular}{lcccccccccc}
$D_{t}$ & $R^{2}$ & $e^{2 \mathrm{SD}}-1$ & $R^{2}$ & $e^{2 \mathrm{SD}}-1$ & $R^{2}$ & $e^{2 \mathrm{SD}}-1$ & $R^{2}$ & $e^{2 \mathrm{SD}}-1$ & $R^{2}$ & $e^{2 \text { SD }}-1$ \\
\hline May & 0.98 & 0.11 & 0.97 & 0.08 & 0.97 & 0.13 & 0.98 & 0.08 & 0.98 & 0.08 \\
June & 0.97 & 0.11 & 0.98 & 0.06 & 0.97 & 0.11 & 0.99 & 0.08 & 0.98 & 0.11 \\
July & 0.95 & 0.06 & 0.99 & 0.01 & 0.91 & 0.13 & 0.96 & 0.13 & 0.96 & 0.13 \\
$\quad$ August & 0.98 & 0.15 & 0.92 & 0.13 & 0.95 & 0.08 & 1.00 & 0.01 & 1.00 & 0.01 \\
September & 0.97 & 0.11 & 0.89 & 0.15 & 0.99 & 0.06 & 0.97 & 0.11 & 0.96 & 0.13 \\
$\quad$ October & 0.98 & 0.11 & 0.93 & 0.11 & 0.95 & 0.17 & 0.97 & 0.13 & 1.00 & 0.01 \\
$U$ & & & & & & & & & & \\
L & 0.73 & 0.35 & 0.66 & 0.27 & 0.52 & 0.30 & 0.78 & 0.27 & 0.55 & 0.37 \\
$S$ & 0.17 & 0.46 & 0.15 & 0.22 & 0.22 & 0.55 & 0.30 & 0.46 & 0.33 & 0.55
\end{tabular}

Fit measure SRMSR

0.018

0.033

0.020

0.017

0.019

Intercepts are transformed as $e^{\beta L 0 k}$ in order to be interpretable as Euro prices and the remaining coefficients as $e^{C t k}-1, e^{\beta L j k}-1, e^{\beta s j k}-1$, and $e^{2 \text { stdev }}-1$ in order to be interpreted as percentage changes. Percentage changes larger than $5 \%$ are shown in bold.

increase in peak prices, but also through a decrease in the need for low-season price reductions. The importance of attributes that can differentiate the offer of a hotel is thus confirmed. The reference hotels (three-star without special attributes) seem to be the most seasonal ones, as the coefficients $e^{\beta s j k}-1$ are mostly negative.

The $e^{2 \mathrm{SD}}-1$ transformed standard deviations of the $U$ disturbances for the $L$ and $S$ factors suggest that some amount of hotel variation remains in both 


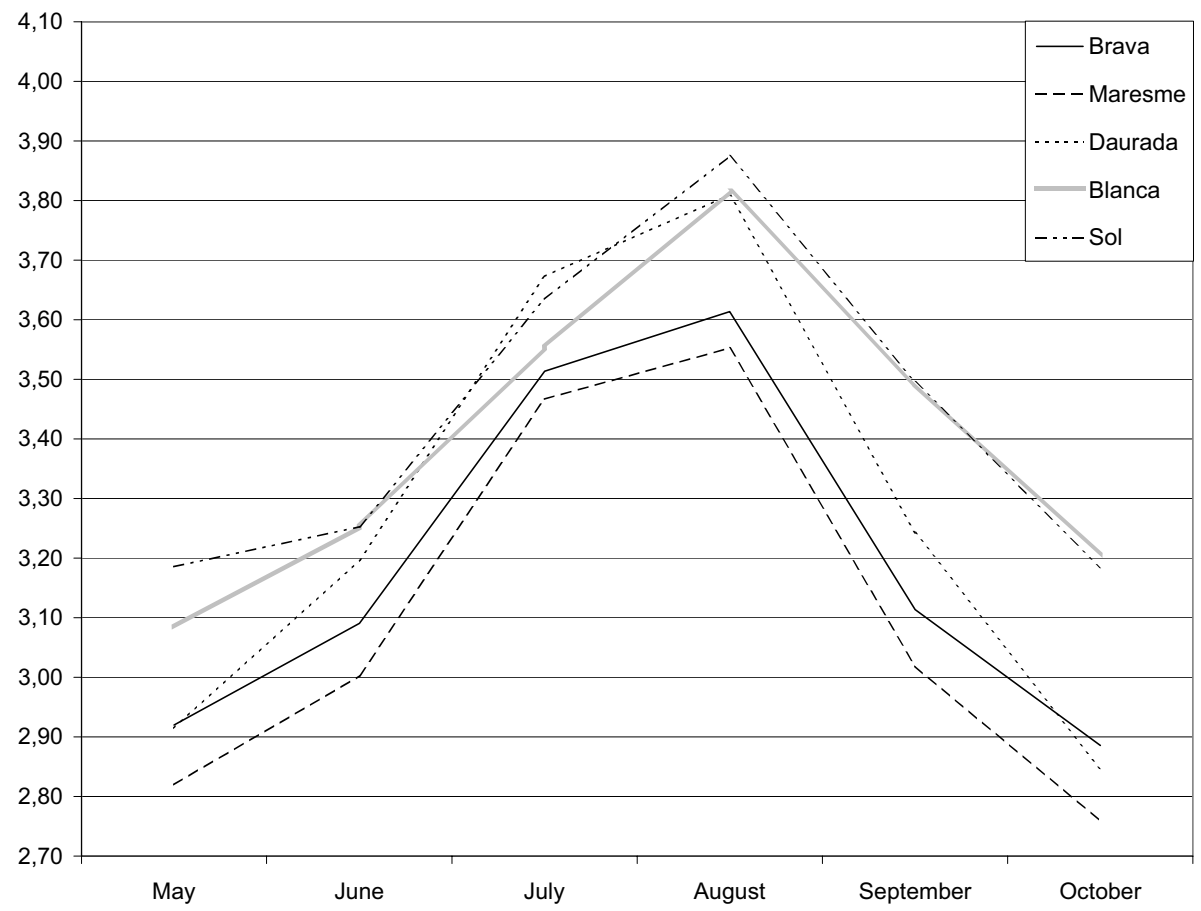

Figure 5. Fitted average $\log$ prices $\left(\beta_{L 0 k}+C_{t k}\right)$ for a three-star hotel without additional services.

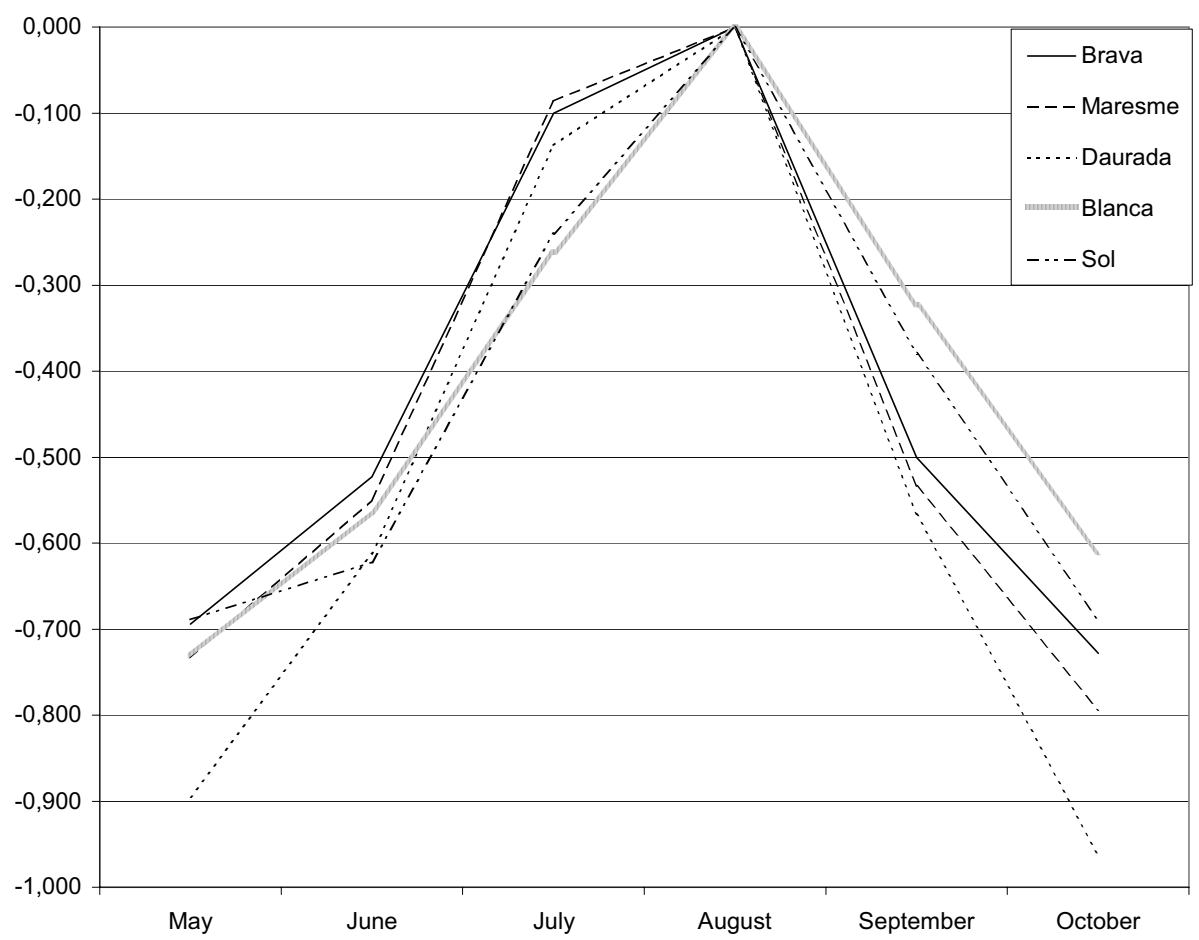

Figure 6. Average differences in log prices with respect to the peak month $\left(C_{t k}\right)$ for a three-star hotel without additional services. 
August price level (variations around $\pm 30 \%$ in peak price are possible between hotels with the same attributes and in the same zone) and amplitude of seasonality (variations around $\pm 45 \%$ in seasonality amplitude are possible).

\section{Results of Modeling the Pooled Data of All Zones}

The fit of the model with pooled data and weather effects is good. SRMSR equals 0.025 and transformed $D_{t}$ and $U$ standard deviations are about as low as for the unconstrained models fitted separately in each zone. This model is much more parsimonious than those in the previous section, as it includes only one effect of each category dummy, which can be interpreted as overall or average effect of the given characteristic. Zone-specific coefficients are thus not obtainable in this section.

In this model, seasonality coefficients $e^{C t}-1$ refer to Costa Brava. In order to obtain seasonality coefficients for other zones, it must be taken into account that the estimated increases in price for each additional degree of temperature $\left(e^{\eta t}-1\right)$ are $12.6 \%$ for September and 5.5\% for October. The effects in May and June are much lower, at $2.0 \%$ and $1.8 \%$, respectively. These results show the importance of climate in the sun-and-beach segment. In September or October, weather will only be summer-like in the southern zones Costa del Sol and Costa Blanca, which will be the zones of choice for many sunseekers having holidays during these months. The fact that differentiation is achievable also through weather must be taken into account when deciding where to locate a hotel.

According to this model, situation in front of the beach leads to average peak increases $\left(e^{\beta L j}-1\right)$ of $6.9 \%$ and reduces the amplitude of seasonal fluctuations $\left(e^{\beta s j}-1\right)$ by $5.9 \%$. Room services increase peak price by $9.9 \%$ and reduce the amplitude of seasonality by $5.1 \%$. Parking place increases peak price by $8.5 \%$ and reduces the amplitude of seasonality by $3.6 \%$. Sport facilities have the lowest effect, increasing peak price by $4.5 \%$ and reducing the amplitude of seasonality by $0.7 \%$. One-star hotels have peak prices $25.5 \%$ lower than three-star hotels and $10.0 \%$ narrower seasonal fluctuations. Two-star hotels have peak prices $11.5 \%$ lower than three-star hotels and $4.6 \%$ narrower seasonal fluctuations. Four-star hotels have peak prices $42.9 \%$ higher than
Table 6

Estimates of Models With Pooled Data

\begin{tabular}{|c|c|}
\hline \multicolumn{2}{|l|}{$e^{\mathrm{Ct}}-1$} \\
\hline May & -0.520 \\
\hline June & -0.425 \\
\hline July & -0.146 \\
\hline August & - \\
\hline September & -0.400 \\
\hline October & -0.552 \\
\hline \multicolumn{2}{|l|}{$e^{\eta t}-1$} \\
\hline May & 0.020 \\
\hline June & 0.018 \\
\hline September & 0.126 \\
\hline October & 0.055 \\
\hline \multicolumn{2}{|l|}{$e^{\beta L 0}$} \\
\hline Intercept & 40.313 \\
\hline \multicolumn{2}{|l|}{$e^{\beta L j}-1$} \\
\hline Beach & 0.069 \\
\hline Room & 0.099 \\
\hline Parking & 0.085 \\
\hline Sport & 0.045 \\
\hline H1 & -0.255 \\
\hline $\mathrm{H} 2$ & -0.115 \\
\hline H4 & 0.429 \\
\hline \multicolumn{2}{|l|}{$e^{\delta L k}-1$} \\
\hline Maresme & -0.170 \\
\hline Daurada & 0.007 \\
\hline Blanca & 0.021 \\
\hline Sol & 0.096 \\
\hline \multicolumn{2}{|l|}{$e^{\beta s j}-1$} \\
\hline Beach & -0.059 \\
\hline Room & -0.051 \\
\hline Parking & -0.036 \\
\hline Sport & -0.007 \\
\hline H1 & -0.100 \\
\hline $\mathrm{H} 2$ & -0.046 \\
\hline $\mathrm{H} 4$ & -0.161 \\
\hline \multicolumn{2}{|l|}{ Covariances } \\
\hline$L-S$ & -0.010 \\
\hline$D_{1}-D_{2}$ & 0.001 \\
\hline$D_{2}-D_{3}^{2}$ & 0.002 \\
\hline$D_{3}-D_{4}$ & 0.000 \\
\hline$D_{4}-D_{5}$ & 0.001 \\
\hline$D_{5}^{4}-D_{6}$ & -0.001 \\
\hline
\end{tabular}

\begin{tabular}{lcc}
$\begin{array}{c}\text { Disturbances } \\
D_{t}\end{array}$ & $R^{2}$ & $e^{2 \text { stdev }}-1$ \\
\hline May & 0.97 & $\mathbf{0 . 1 3}$ \\
June & 0.97 & $\mathbf{0 . 1 3}$ \\
July & 0.93 & $\mathbf{0 . 2 0}$ \\
August & 0.97 & $\mathbf{0 . 0 8}$ \\
September & 0.97 & $\mathbf{0 . 1 3}$ \\
October & 0.98 & $\mathbf{0 . 1 1}$ \\
$U$ L & & \\
$S$ & 0.73 & $\mathbf{0 . 3 2}$ \\
$S$ & 0.14 & $\mathbf{0 . 4 6}$
\end{tabular}

Fit meas. SRMSR

0.025

The intercept is transformed as $e^{\beta L 0}$ in order to be interpretable as Euro prices and the remaining coefficients as $e^{C t}-1, e^{\eta t}-1, e^{\delta L k}-1$, $e^{\beta L j}-1, e^{\beta s j}-1$, and $e^{2 \text { stdev }}-1$ in order to be interpreted as percentage changes. Percentage changes larger than $5 \%$ are shown in bold. 
three-star hotels and $16.1 \%$ narrower seasonal fluctuations.

As shown by the $e^{\delta L k}-1$ coefficients, in August, hotels in Maresme are $17.0 \%$ cheaper than in Costa Brava, in Costa Daurada 0.7\% more expensive, in Costa Blanca $2.1 \%$ more expensive, and in Costa del Sol $9.6 \%$ more expensive.

\section{Conclusions and Discussion}

In this article LGCM were fitted to study the peak level and seasonality of hotel prices and their predictors. SEM were used with this purpose. In our case, the major advantage of using SEM instead of HLM has been that the $C_{t}$ coefficients could be specified as free parameters to be estimated, which is necessary as seasonal coefficients cannot be known in advance. The formulation of equations predicting the random effects is also very straightforward under SEM, though it can be done with HLM as well. Extensions of the model, such as relating seasonalities and levels of hotel prices to those of other type of prices, would use the full strength of the SEM approach.

The choice of $C_{4}=0$ does affect which month is taken as representing price level and thus can also influence all estimates of the equation predicting level (Rovine \& Molenaar, 1998). Our choice for the peak month is statistically arbitrary but it makes sense from an economic point of view. The choice on which constraints to impose on the seasonality factor (the mean equal to 1 , which to our best knowledge has been first applied here, or one loading equal to 1 , in which case it has to be decided which one) may change estimated standard errors (Stoel, van den Wittenboer, \& Hox, 2002), which are not relevant in a population study like ours.

Hotel category affects peak price level in the expected way and price differences are substantial. Seasonality is highest for three-star hotels without any of the additional attributes considered. It can be suggested that one- and two-star hotel guests are too sensitive to price for prices to increase too much during the peak season. Similarly, four-star hotel guests may be so little sensitive to price that there is no need for a larger reduction out of the peak season. The highest category thus seems to be the most profitable one. Actually, in all considered zones, most newly built hotels are four-star ones, and many of the older three-star ones are undergoing reforms in order to be reclassified as four-star.

The attributes that showed most important to explain peak level and seasonality were closeness to the beach, room equipment, and availability of parking place. The analyzed attributes include some that are decided only once when the hotel is first built (zone and situation in front of the beach). In the sunand-beach segment, the willingness to pay a substantial surplus for being in front of the beach was, of course, to be expected. Some other attributes, on the contrary, can be relatively easily added or eliminated (sport facilities and room equipment). Hotel managers should consider the addition of extra room equipment, as this seems to increase revenues in return to a relatively low investment.

All effects differ from zone to zone, although the general patterns are roughly similar so that the average effects in Section 5 can be considered to be representative. However, managers of hotels in a particular zone should find the results in Section 4 more useful.

Zone has also been found to be an important determinant of price. The fact that certain tour operators specialize in certain zones might also contribute to differential zone prices, but this effect has been partialed out of the prices before fitting the model. The effect of zone on peak level shows that hotel attributes are not the sole determinants of price, and that tourists do not only pay for a hotel room but also for its environment. Although further research is needed on the effect on prices of these aspects of supply, this fact must inspire the local and regional government policies. These five zones do not only compete against one another, but also against all other parts of the world where the climate is good enough to make them competitive in the sun-andbeach segment. This increases the need for zones to differentiate. In Spain, local and regional authorities have embarked in huge marketing campaigns to promote their zones, have tightened the regulation of environmental protection, and have attracted investors to build big amusement parks and other kinds of recreational infrastructure. The ultimate aim of these policies is to differentiate the zones by making them attractive for other things than merely sunseeking. In some zones, local policy also plays a role in another respect, namely by limiting permits to build new hotels. In our opinion, it is very impor- 
tant that the public and private agents go hand in hand working to improve the future perspectives of the zone they are in.

Weather has been shown to be a determinant of demand and price (as has been said, to a large extent, prices negotiated between hotels and tour operators depend on past demand; see Espinet, 1999). The fact that sunbathing is reported as the main activity for $75.2 \%$ of nonbusiness visitors (Departament d'Indústria, Comerç i Turisme, 1999) supports the importance of weather variables on demand. If the zone effect on seasonality is attributed to weather and the zone effect on peak level is attributed to other characteristics of the zone, then estimates of the effect of weather on price can be obtained. These estimates can be useful when deciding in which zone to build a hotel. Availability of holidays is of course a prerequisite for there being demand. In Spain, schools do not open until mid or late September, which allows families with children to enjoy some weeks of holidays in September, thus increasing demand in zones with a mild weather, and also price. This could explain the high differences in weather effect between late spring and early autumn.

Of course, these weather estimates are obtained under the assumptions that weather does not affect peak level, that other characteristics of the zone do not affect seasonality, that $27^{\circ} \mathrm{C}$ is a pleasant temperature for sunbathing, and that the effect of temperature is flat above that. If these assumptions do not hold, the results are questionable. Many zonespecific variables, such as environmental quality, landscape, or urban services, are indeed nonseasonal. In any case, it must be admitted that the estimates of the effect of weather may be contaminated by differential managerial strategies to face the diminished low-season demand. Actually, all zones have virtually no vacancy during the peak months, but different zones have different levels of vacancy in the low season. The percentage of vacancy in October 1999 was about 10\% higher in Costa Brava than in Costa del Sol or Costa Blanca. Besides, $13 \%$ of Costa Brava hotels had already closed by early October, whereas only $1 \%$ of hotels in Costa Blanca and Costa del Sol had done so. If Costa del Sol and Costa Blanca manage to keep September and October prices higher, in spite of a higher supply, and yet attract more customers, then it is suggested that the model may even have subestimated the economic value of weather.

The results in this article can be useful to investors, as they show how location decisions can affect price. The results can also be useful to hotel owners and managers, as they show which attributes can differentiate a hotel and thus increase peak prices and reduce seasonality, and they provide useful information for pricing decisions, especially under complex pricing models such as yield management. The results can also be useful to governments and tourist offices, as they show that zone-specific variables also have an influence on price, though no detail on the weight of each of the possible zone variables can be provided from a population of only five zones. Further research is needed on this very important aspect of regional policy. The research on hotel attributes would have to be periodically redone as new market trends may cause a shift in the preferred attributes. An extension to other countries would also be desirable.

\section{Acknowledgements}

The authors wish to thank Carme Saurina, Joan Manuel Batista-Foguet, Reinoud Stoel, and Vesna Zabkar for their comments on earlier versions of this article.

\section{References}

Batista-Foguet, J. M., \& Coenders, G. (2000). Modelos de ecuaciones estructurales [Structural equation models]. Madrid, Spain: La Muralla.

Bock, R. D. (1989). Multilevel analysis of educational data. San Diego: Academic Press.

Bollen, K. A. (1989). Structural equations with latent variables. New York: Wiley.

Cassel, E., \& Mendelsohn, R. (1985). The choice of functional forms for hedonic price equations: Comment. Journal of Urban Economics, 18, 135-142.

Chias, J. (1996). Existe o no una estrategia de precios en el turismo español? [Is there a pricing strategy in Spanish tourism?]. EDITUR, 1894, 11-15.

Clewer, A., Pack, A., \& Sinclair, T. (1992). Price competitiveness and inclusive tourism holidays in European cities. In P. Johnson \& B. Thomas (Eds.), Choice and demand in tourism (pp. 123-144). London: Mansell.

Departament d'Indústria, Comerç i Turisme (1999). Resum de la temporada turística 1999 [Summary of the 1999 tourist season]. Barcelona, Spain: Generalitat de Catalunya.

Duncan, T. E., Duncan, S. C., Strycker, L. A., Li, F., \& Alpert, 
A. (1999). An introduction to latent variable growth curve modeling. Concepts, issues and applications. Mahwah, NJ: Lawrence Erlbaum.

Enders, C. K., \& Bandalos, D. L. (2001). The relative performance of full information maximum likelihood estimation for missing data in structural equation models. Structural Equation Modeling, 8, 430-457.

Espinet, J. M. (1999). Anàlisi dels preus al sector hoteler de la Costa Brava sud [Analysis of hotel prices in southern Costa Brava]. Unpublished doctoral dissertation, University of Girona, Girona, Spain.

Espinet, J. M., Saez, M., Coenders, G., \& Fluvià, M. (in press). The effect on prices of the attributes of holiday hotels: A hedonic prices approach. Tourism Economics.

Ghisletta, P., \& McArdle, J. J. (2001). Latent growth curve analysis of the development of height. Structural Equation Modeling, 8, 531-555.

Graham, J. W., Taylor, B. J., \& Cumsille, P. E. (2001). Planned missing data designs in the analysis of change. In L. M. Collins \& A. Sayer (Eds.), New methods for the analysis of change (pp. 333-354). Washington, DC: American Psychological Association.

Halvorsen, R., \& Pollakowski, H. O. (1981). Choice of functional form for hedonic price equations. Journal of $U r$ ban Economics, 10, 37-49.

Hox, J. J. (2000). Multilevel analysis of grouped and longitudinal data. In T. D. Little, K. U. Schnabel, \& J. Baumert (Eds.), Modeling longitudinal and multilevel data, practical issues, applied approaches and specific examples (pp. 15-32). Mahwah, NJ: Lawrence Erlbaum.

Hu, L., \& Bentler, P. M. (1998). Fit indices in structure modeling: Sensitivity to underparameterized model specification. Psychological Methods, 3, 424-453.

Jaime-Pastor, V. (1999). Un análisis de los precios hoteleros empleando funciones hedónicas [An analysis of hotel prices using hedonic functions]. Estudios Turísticos, 139, 65-87.

Laird, N. M., \& Ware, J. H. (1982). Random-effects model for longitudinal data. Biometrics, 38, 963-974.

Lieberman, W. H. (1993). Debunking the myths of yield management. The Cornell Hotel and Restaurant Administration Quarterly, 34, 34-41.

McArdle, J. J. (1988). Dynamic but structural equation modeling of repeated measures data. In R. B. Cattell \& J. Nesselroade (Eds.), Handbook of multivariate experimental psychology (2nd ed., pp. 561-614). New York: Plenum Press.

McArdle, J. J. (1998). Recent trends in modeling longitudinal business data by latent growth curve methods. In G. Marcoulides (Ed.), New statistical models with business and economic applications (pp. 359-406). Mahwah, NJ: Lawrence Erlbaum.

McArdle, J. J., \& Epstein, D. (1987). Latent growth curves with developmental structural equation models. Child Development, 58, 110-133.

Meredith, W., \& Tisak, J. (1990). Latent curve analysis. Psychometrika, 55, 107-122.

Muthén, B. (1997). Latent variable modeling of longitudinal and multilevel data. In A. Raftery (Ed.), Sociological methodology 1997 (pp. 453-480). Boston: Basil Blackwell.

Muthén, B. (2000). Integrating person-centered and variablecentered analyses, growth mixture modeling with latent trajectory classes. Alcoholism, Clinical and Experimental Research, 24, 1-10.

Muthén, L. K., \& Muthén, B. (1998). Mplus user's guide. Los Angeles: Authors.

Raudenbush, S. W. (2001). Toward a coherent framework for comparing trajectories of individual change. In L. M. Collins \& A. Sayer (Eds.), New methods for the analysis of change (pp. 33-64). Washington, DC: American Psychological Association.

Rosen, S. (1974). Hedonic prices and implicit markets: Product differentiation in pure competition. Journal of Political Economy, 82, 34-55.

Rovine, M. J., \& Molenaar, P. C. M. (1998). The covariance between level and shape in the latent growth curve models with estimated basis vector coefficients. Methods of Psychological Research Online, 3.

Rovine, M. J., \& Molenaar, P. C. M. (2001). A structural equations modeling approach to the general linear mixed model. In L. M. Collins \& A. Sayer (Eds.), New methods for the analysis of change (pp. 65-96). Washington, DC: American Psychological Association.

Satorra, A. (1990). Robustness issues in structural equation modeling: A review of recent developments. Quality and Quantity, 24, 367-86.

Sinclair, M. T., Clewer, A., \& Pack, A. (1990). Hedonic prices and the marketing of package holidays: The case of tourism resorts in Malaga. In G. Ashworth \& B. Goodall (Eds.), Marketing of tourism places (pp. 85-103). London: Routledge.

Sörbom, D. (1974). A general method for studying differences in factor means and factor structures between groups. British Journal of Mathematical and Statistical Psychology, 27, 229-239.

Stoel, R., van den Wittenboer, G. L. H., \& Hox, J. J. (2002). Application of the latent growth curve model: Methodological issues. Paper presented at the International Conference on Methodology and Statistics, September 1518, 2002, Ljubljana, Slovenia.

Taylor, P. (1995). Measuring changes in the relative competitiveness of package tour destinations. Tourism Economics, 1, 169-182.

Willett, J. B., \& Sayer, A. G. (1993). Using covariance structure analysis to detect correlates and predictors of individual change over time. Psychological Bulletin, 116, 368-381.

Witt, S. F., \& Moutinho, L. (1994). Tourism marketing and management handbook. Upper Saddle River, NJ: Prentice Hall.

Wothke, W. (2000). Longitudinal and multi-group modeling with missing data. In T. D. Little, K. U. Schnabel, \& J. Baumert (Eds.), Modeling longitudinal and multilevel data, practical issues, applied approaches and specific examples (pp. 219-240). Mahwah, NJ: Lawrence 
Erlbaum

Yuan, K. H., \& Bentler, P. M. (2000). Three likelihood-based methods for mean and covariance structure analysis with nonnormal missing data. In M. E. Sobel \& M. P. Becker (Eds.), Sociological methodology 2000 (pp. 165-200). Washington, DC: American Sociological Association. 